Çukurova Üniversitesi Mühendislik Mimarlık Fakültesi Dergisi, 30(1), 17-23 ss., Haziran 2015

Çukurova University Journal of the Faculty of Engineering and Architecture, 30(1), pp. 17-23, June 2015

\title{
Yüklenici Firmaların Tedarik Zinciri Yönetimi Uygulamalarında Kritik Başarı Faktörleri
}

\author{
Ebrahim SALAMI ${ }^{1}$, Emel LAPTALI ORAL ${ }^{* 1}$, Serkan AYDINLI ${ }^{1}$ \\ ${ }^{1}$ Çukurova Üniversitesi, Mühendislik Mimarlık Fakültesi, İnşaat Mühendisliği Bölümü, Adana
}

Özet

Geliş tarihi: 15.12 .2015

Kabul tarihi: 17.06 .2015

İnşaat sektörü ülkelerin ekonomik gelişmesinde önemli bir role sahiptir. İnşaat proje bazlı bir üretim olup, hammadde, makine, finans, teknoloji ve insan kaynağının etkin ve verimli kullanımını gerektirir. Tedarik Zinciri Yönetimi yenilikçi bir yönetim stratejisi olarak inşaat projelerinin verimliliğini ve etkinliğini artırmak için yapım yönetiminde temel bir unsur haline gelmiştir.

$\mathrm{Bu}$ çalışma Türkiye'de hizmet veren yüklenici firmaların tedarik zinciri yönetimi uygulanmasında başarıya ulaşabilmeleri için ön plana çıkan kritik başarı faktörlerinin belirlenmesine odaklanmaktadır. Konu ile ilgili veri toplanması amacıyla bir anket düzenlenmiştir. Toplanan veriler faktör analizi yapılarak değerlendirilmiş ve kritik başarı faktörleri belirlenmiştir.

Anahtar Kelimeler: İnşaat sektörü, Tedarik zinciri yönetimi, Tedarikçi ve alt yüklenici seçimi, Yapım ve proje yönetimi.

\section{Critical Success Factors for Successful Supply Chain Management Applications of Construction Firms}

\begin{abstract}
Construction sector has an important role in the economic development of each country. Construction is a project based production which requires effective and efficient use of materials, machinery, technology and human resources. Supply Chain Management as an innovative management approach has become an important element in the construction project management to improve the efficiency and productivity of construction projects.

This research focuses on exploration of critical success factors for successful application of supply chain management by Turkish contractors. A questionnaire form was formed in order to collect related data. Collected data was analysed through hypothesis tests and factor analysis and critical successs factors were determined accordingly.
\end{abstract}

Keywords: Turkish construction sector, Supply chain management, Supplier and subcontractor selection, Construction and project management.

\footnotetext{
* Yazışmaların yapılacağı yazar: Emel LAPTALI ORAL, Mühendislik Mimarlık Fakültesi, İnşaat Mühendisliği Bölümü, Adana.eoral@cu.edu.tr
} 


\section{GİRIŞ}

Günümüzde işletmelerin yoğun rekabet koşullarında başarılı olabilmeleri için tedarik, tasarım, üretim, pazarlama ve lojistik vb. faaliyetlerini etkin bir şekilde yönetmeleri ve ürün verimliliklerini, maliyetlerini ve fiyatlarını daha iyi kontrol etmeleri gerekmektedir. Tedarik zinciri yönetimi yaklaşımı, müşteri istek ve ihtiyaçlarının belirlenmesinden başlayarak, kaynakların temini, mal ve hizmetlerin üretimi ve son kullanıcılara ulaştırılması sürecine kadar tedarikçiler, üreticiler, dağıtıcılar ve müşteriler arasında malzeme, ürün, bilgi ve finansal akışların etkin bir şekilde yönetilmesini sağlar. Bu yaklaşım, zincir içerisinde bulunan işletmelerin verimliliklerinin ve karlılıklarının artırılmasında ve faaliyetlerin güvenli bir şekilde sürdürülmesinde önemli derecede etkilidir.

İnşaat sektöründe tasarım, inşa ve tedarik tarafları farklı inşaat projeleri üzerinde sürekli değişen ortaklıklar şeklinde çalışırlar [1]. Geleneksel yapım ortamında, yüklenici-mimar veya yüklenici-tedarikçi gibi çeşitli ikili anlaşmalar yapılır. Mimar, müşteri (işveren) isteğine bağl1 olarak tasarlar/tasarım yapar ve yüklenici, tedarikçi ve taşeronların desteği ile tasarımı gerçekleştirir. $\mathrm{Bu}$ geçici ortaklıklar sadece projenin tamamlanmasına kadar sürer. Her bir paydaş inşa sürecinin yürütülmesi aşamasında sözleşme kapsamında yüklendiği sorumluluğa göre kendine özgü kaynaklar ayırır [2].

Tedarikçilerle iletişimin ve malzemenin sahaya dağıtımının zamanında ve en az maliyetle elde edilmesi için tedarikçi sayısının en aza indirgenmesi gereklidir [3]. Birden fazla tedarikçi sistemi, tek bir tedarikçi sisteminden daha pahalıdır. Örneğin, belirli bir madde için çok sayıda tedarikçi yönetmek, işgücü, sipariş ve işleme maliyetleri de dahil olmak üzere doğrudan maliyetleri artırır. Aynı zamanda çoklu kaynak, tedarikçiler arasında kalitede ortaya çıkan farklar nedeniyle genel kalite düzeyini düşürür [4].

Lummus ve Vokurka [5], tedarik zincirinin entegrasyonunu sağlayabilen işletmelerde; daha az stok yatırımı yapıldığını, nakit akış zamanın azaldığını, malzeme alım maliyetinin düştüğünü, daha düşük lojistik maliyetlerine yol açtığını ve müşterinin taleplerine uyabilme yeteneğine sahip olduklarını belirtmişlerdir.

Tedarik zinciri yönetimi, inşaat sektöründe maliyet ve zaman aşımlarını ortadan kaldırabilir ve ayrıca inşaat sürecindeki performansı artırır [6]. Türkiye inşaat faaliyetlerinin yoğun gerçekleştiği bir ülke olduğu için yüklenici firmalar tarafindan tedarik zinciri yönetimi uygulanmasının projelerin performansına, dolayısı ile sektör çalışanlarına ve ülke ekonomisine önemli etkisi olabileceği düşünülmektedir.

İnşaat tedarik zinciri yönetimini etkileyecek temel başarı faktörleri; tedarikçilerin sayısının azaltılması, tedarikçiler ile uzun süreli iyi ilişkiler, üst yönetimin desteği ve kalite anlayışıdır [7].

Şirketler az sayıdaki tedarikçileri ile uzun vadeli sözleşmeler yaparak farklı işlerde sürdürülebilir faydalar elde edebilirler. Sürekliliği olan, uzun vadeli bir ilişki sayesinde bir tedarikçi iyi yönetilen bir tedarik zincirinin bir parçası haline gelir ve tüm tedarik zincirinin ve firmanın rekabet gücü üzerinde kalıcı bir etkiye sahip olur [8]. Seçilen tedarikçilerle uzun süreli anlaşmaların yapılması, uygun fiyat ve kalite düzeyini sürdürdüğü gibi, malzemenin kalite ve miktarları ile ilgili yüklenici tarafından yapılan kontrolü de en aza indirmektedir.

İnşaat sektöründe tedarik zinciri yönetimi geliştirilmesinde ve ilişkilerin başarılı olabilmesinde taraflar arasında karşılıklı güven, üst yönetim desteği karşılıklı çıkarların gözetilmesi, insan gücü geliştirme, kesintisiz bilgi akışı ve sık toplantılar gibi faktörler en önemli etkenlerdir [9]. Güvene dayalı bir işbirliği tedarik zincirinin tüm faaliyetleri için bir temeldir.

Lambert ve arkadaşları [10], tedarik zinciri yönetimi uygulama sürecinde, firmaların üst düzey yönetim, tedarik zinciri ağ yapısı, iş süreçleri ve yönetim bileşenlerine odaklanma gerekliliğini vurgulamışlardır. 
İnşaat tedarik zinciri yönetiminin, proje ortaklığ ve toplam kalite yönetimi ile birlikte benimsendiğinde, müşterilerin sorunlarının ele alınmasında etkili olacağını vurgulamışlardır [10] Wong ve Fung [11]'a göre, tedarik zinciri yönetimi, bir yüklenicinin, toplam kalite hedeflerinin önemli bir parçası olmalıdır.

Dale ve arkadaşlarının (1994) tedarik zinciri yönetimi ile ilgili yaptıkları bir araştırmaya göre, başarılı bir tedarik zinciri oluşturmada;

- Taraflar arasında uzun süreli sözleşmeler,

- Taraflar arasında iş faaliyetleri ve planları hakkında daha fazla bilgi edinme arzusu ve karşılıklı bilgi alışverişi,

- Ürün geliştirme ve tasarım süreçlerinde tedarikçi katılımı,

- Tedarikçilerin, teknolojik eğilimleri izleyerek sürekli iyileştirme yönündeki çabalarının sürekliliği,

- Tedarikçi tabanının azaltılması,

- Ortaklar arasında güven gelişimi, gibi faktörler kritik bir role sahiptirler [12].

Etkin bir tedarik zinciri yönetimi, işletmenin üretim ve pazarlamaya ilişkin faaliyetlerini olumlu yönde etkilemesi ile daha fazla müşteri memnuniyeti, daha etkin ve verimli bir işletme oluşmasını sağlarken, daha düşük maliyetler ve daha yüksek kâr ile birlikte istikrarlı gelişimi sağlar.

\section{MATERYAL VE METOT}

\subsection{Materyal}

İnşaat sektöründe yüklenici firmaların tedarik zinciri yönetimi yaklaşımının belirlenmesi, uygulamanın önündeki engeller, uygulamadan elde edilen faydalar ve tedarikçi ilişkilerinin belirlenmesi bu araştırmanın konusunu oluşturmaktadır.

Araştırmada kavramsal içeriğin oluşturulması safhasının kaynağını kütüphane ve internetten sağlanan veriler oluşturmaktadır. İnşaat sektöründe hizmet veren ana yüklenici firmalar için hazırlanan anketin Türkiye genelinde katılımcilara uygulanması sonucunda elde edilen veriler ise araştırmanın materyallerini oluşturmaktadır.

\subsection{Metot}

Çalışma, inşaat sektöründe yüklenici firmaların tedarik zinciri yönetimi uygulamaları ve tedarikçi ilişkilerine yönelik bir çalışmadır. Çalışmada verilerin objektif olarak toplanıp, istatistik analiz teknikleri ile hesaplamalar yapılabilmesi için anket yöntemi uygulanmıştır. Hazırlanan anketler katılımcılarla yüz yüze görüşme yöntemi ile uygulanmıştır. Yüklenici firmalardan anket yoluyla toplanan veriler, istatistik yöntemler kullanılarak analiz edilmiştir. Verilerin analizinde, SPSS 18 paket programından yararlanmıştır.

Araştırma doğrultusunda, yüklenici firmaların sektörde tedarik zinciri ilişkilerinde başarılı olabilmesi için kritik olan faktörlerin belirlenebilmesi amaciyla ilgili sorulara Açımlayıcı Faktör Analizi uygulanmıştır. Faktör Analizi, değişkenler arasındaki karşılıklı ilişkileri inceleyerek, değişkenlerin daha anlamlı ve özet bir şekilde sunulmasını sağlar. Değişkenler arasındaki ilişkilerin altında yatan birlikteliğin ortak örüntülerini belirleyip değişkenleri ortak faktörler altında toplar ve bu faktörler araştırmacı tarafından isimlendirilir [13].

\section{BULGULAR VE TARTIŞMA}

\subsection{Bulgular}

$\mathrm{Bu}$ araştırmada literatür bulgularına dayanarak inşaat sektöründe tedarik zinciri yönetimi uygulamalarında ve tedarik zinciri ilişkilerinin başarılı olabilmesinde önemli olan etmenler araştırılmış, konu ile ilgili 104 yüklenici firma ile yüz yüze görüşülerek bir anket çalışması yapılmıştır. Çalışan sayısına göre değerlendirildiğinde ankete katılan firmaların \%52'si küçük, \%21'i orta, \%27'si de büyük ölçekli firmalardan oluşmaktadır. Çizelge 1 'de tedarik zincirinin başarısında etkili olan etmenlerle ilgili cevapların aritmetik ortalama ve mod değerleri verilmiştir. 
Çizelge 1'deki sonuçlara bakıldığında, yüklenici firmalar için tedarik zinciri ilişkilerinin başarılı olabilmesindeki en önemli etmenin "karşılıklı güven” olduğu görülmektedir.

Tedarik zinciri karmaşıklığı arttıkça, zincir içerisindeki tüm üyelerin gereksinimlerinin dengelenmesi güçleşmektedir. Böylece, üyeler arasında karşılıklı güvenin sağlanmasında izleme ve ölçme faaliyetleri kritik başarı unsurları olmaktadır [14]. Elde edilen verilerin dağılımı da bu duruma destekleyici şekildedir. Karşılıklı güvenden sonra, tedarik zinciri üyeleri arasında sorumluluk duygusu ve taahhüdün olması sırayla 4,69 ve 4,58 aritmetik ortalamalara sahip olarak diğer iki yüksek değere sahip olan en önemli etkenlerdir. Tedarik zincirinde karşılıklı güven ve taahhüdün oluştuğu ilişkilerde, daha fazla işbirliği yapılmakta, daha az çatışma yaşanmakta, belirsizlik altında daha doğru kararlar alınmakta, ortaklığı sona erdirme eğilimi azalmakta ve yenilik için istekli olunmaktadır [15].

Çizelge 1'de sıralanan etmenlerin gruplandırılması ve daha detaylı değerlendirilebilmesi amacı ile ilgili verilere Faktör Analizi uygulanmıştır. Faktör analizinin uygulanacağı örneklemin yeterliliğini belirlemek için Kaiser-Meyer-Olkin (KMO) ve Bartlett's Küresellik testleri yapılmıştır. KMO test değeri 0.795 ve Bartlett's Küresellik Test sonucu $\chi 2=461,688$ 'çıkmıştır. $\mathrm{Bu}$ değerler veri grubunun faktör analizine uygun olduğunu göstermiştir [13].

Faktör analizinde, analiz sonucunda siralanan faktörlerin geçerli olarak kabul edebilmesi için öz değerlerinin bir veya birden büyük olması kriteri aranmaktadır [13]. Çizelge 2'ye bakıldığında bu şartı sağlayan 5 adet faktörün olduğu görülmektedir. En önemli 5 faktörün kümülatif varyans değeri ise bu faktörlerin toplam varyansın \%59,078'ini açıklıyor olduğunu göstermektedir.

Çizelge 3'de faktörler altında toplanmış bileşenlerin (etmenlerin) elde edilen döndürülmüş faktör yükleri görülmektedir. Buna göre, birinci faktörün bileşen yükleri 0,790 ile 0,572 arasında değişmektedir. İnşaat sektöründe tedarik zinciri ilişkilerinin başarılı olabilmesinde önemli olan faktörlerden; "ihale sürecinin basitleştirilmesi", "uzun vadeli bir bakış açısı ve gerçekçi bir vizyon", "esneklik" ve "amaç ve hedeflerin şeffaflığı" olmak üzere toplam dört değişken bu faktöre yüklenmiştir. Faktöre yüklenen değişkenlerin içerikleri değerlendirildiğinde, bu faktör "Stratejik Hedefler ve Esneklik" şeklinde isimlendirilmiştir.

Çizelge 1. Ankete katılan yüklenici firmalar açısından tedarik zinciri ilişkilerinin başarısını etkileyen etmenler

\begin{tabular}{|c|c|c|c|}
\hline & Etmenler & $\frac{\overparen{\Xi}}{\overparen{\Xi}}$ & $\bar{z}$ \\
\hline 1 & Karşılıklı güven & 4,82 & 5 \\
\hline 2 & Sorumluluk duygusu & 4,69 & 5 \\
\hline 3 & Taahhüt & 4,58 & 5 \\
\hline 4 & $\begin{array}{l}\text { Amaç ve hedeflerin } \\
\text { şeffaflığ }\end{array}$ & 4,50 & 5 \\
\hline 5 & Ortak iş planlaması & 4,32 & 5 \\
\hline 6 & Kesintisiz bilgi akış1 & 4,28 & 5 \\
\hline 7 & $\begin{array}{l}\text { Uzun vadeli bir bakış açısı } \\
\text { ve gerçekçi bir vizyon }\end{array}$ & 4,28 & 5 \\
\hline 8 & $\begin{array}{l}\text { Tedarikçi seçimine ve } \\
\text { türüne dikkat edilmesi }\end{array}$ & 4,25 & 5 \\
\hline 9 & Üst yönetim desteği & 3,87 & 5 \\
\hline 10 & $\begin{array}{l}\text { Karşılıklı çıkarların } \\
\text { gözetilmesi }\end{array}$ & 4,26 & 4 \\
\hline 11 & $\begin{array}{l}\text { Firmalar arasında } \\
\text { işbirlikçi kültürünün } \\
\text { olması }\end{array}$ & 4,01 & 4 \\
\hline 12 & Etişmiş insan gücü & 3,89 & 4 \\
\hline 13 & $\begin{array}{l}\text { Arz /talep arasında daha } \\
\text { yakın bağlantılar }\end{array}$ & 3,82 & 4 \\
\hline 14 & $\begin{array}{l}\text { Tedarikçilerle daha sık } \\
\text { toplantılar }\end{array}$ & 3,78 & 4 \\
\hline 15 & $\begin{array}{l}\text { Sektörde bu konuda } \\
\text { başarılı örneklerin olması }\end{array}$ & 3,69 & 4 \\
\hline 16 & Esneklik & 3,66 & 4 \\
\hline 17 & $\begin{array}{l}\text { İhale sürecinin } \\
\text { basitleştirilmesi }\end{array}$ & 3,53 & 4 \\
\hline
\end{tabular}


Çizelge 2. İnşaat sektöründe tedarik zinciri ilişkilerinin başarısını etkileyen etmenlerin oluşturduğu faktörlerin "Açılanan toplam varyans çizelgesi"

\begin{tabular}{|c|c|c|c|c|c|c|c|c|c|}
\hline \multirow[b]{2}{*}{  } & \multicolumn{3}{|c|}{ Öz Değerler } & \multicolumn{3}{|c|}{$\begin{array}{l}\text { Çıarım Karesel } \\
\text { Yüklerin Hesabı }\end{array}$} & \multicolumn{3}{|c|}{ Döndürülmüş Karesel Yüklerin Hesabı } \\
\hline &  & 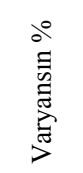 & 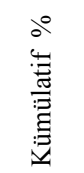 & 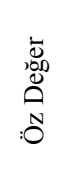 & 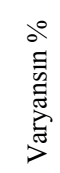 & 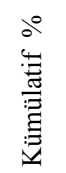 & 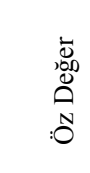 & 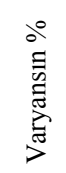 & 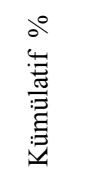 \\
\hline 1 & 4,79 & 28,20 & 28,20 & 4,79 & 28,2 & 28,2 & 2,85 & 16,7 & 16,79 \\
\hline 2 & 1,48 & 8,73 & 36,94 & 1,48 & 8,73 & 36,9 & 2,33 & 13,7 & 30,55 \\
\hline 3 & 1,33 & 7,87 & 44,81 & 1,33 & 7,87 & 44,8 & 2,01 & 11,8 & 42,37 \\
\hline 4 & 1,28 & 7,53 & 52,34 & 1,28 & 7,53 & 52,3 & 1,60 & 9,46 & 51,84 \\
\hline 5 & 1,14 & 6,73 & 59,07 & 1,14 & 6,73 & 59,0 & 1,23 & 7,23 & 59,07 \\
\hline 6 & 0,99 & 5,86 & 64,94 & & & & & & \\
\hline 7 & 0,90 & 5,31 & 70,26 & & & & & & \\
\hline 8 & 0,78 & 4,58 & 74,84 & & & & & & \\
\hline 9 & 0,71 & 4,17 & 79,02 & & & & & & \\
\hline 10 & 0,63 & 3,72 & 82,74 & & & & & & \\
\hline 11 & 0,55 & 3,27 & 86,01 & & & & & & \\
\hline 12 & 0,51 & 3,01 & 89,03 & & & & & & \\
\hline 13 & 0,46 & 2,72 & 91,76 & & & & & & \\
\hline 14 & 0,40 & 2,39 & 94,15 & & & & & & \\
\hline 15 & 0,39 & 2,30 & 96,46 & & & & & & \\
\hline 16 & 0,32 & 1,90 & 98,36 & & & & & & \\
\hline 17 & 0,27 & 1,63 & 100,0 & & & & & & \\
\hline
\end{tabular}

"Taahhüt”, “daha sık toplantılar" ve "karşılıklı çıkarların gözetilmesi” sirasıyla 0,773, 0,706 ve 0,510 yükleri ile ikinci faktöre yüklenmişlerdir. Faktör "Ortak Amaca Taahhüt" şeklinde isimlendirilmiştir.

Üçüncü faktör bileşen yükleri $0,775,0,714$ ve 0,708 olarak belirlenmiştir. "Firmalar arasında işbirlikçi kültürünün olması”, tedarikçi seçimine ve türüne dikkat edilmesi", "sektörde bu konuda başarılı örneklerin olması" bu faktöre yüklenmiştir. $\mathrm{Bu}$ faktör "Işsirliği için Uygun Zincir Üyeleri Oluşturma" şeklinde isimlendirilmiştir.

Dördüncü faktör bileşen yükleri ise 0,871 ve 0,517 olarak belirlenmiştir. "Karşılıklı güven" ve "sorumluluk duygusu” bu faktöre yüklenmiştir.
$\mathrm{Bu}$ faktör firmalar arasındaki manevi bağları/değerleri ifade edecek şekilde "Güven ve Sorumluluk" olarak isimlendirilmiştir.

Son olarak beşinci faktör yükleri 0,758 ve 0,574 olarak belirlenmiştir. "Üst yönetim desteği" ve "insan gücü geliştirme" bu faktöre yüklenmiş olup, insan faktörü ön plana çıkmış ve faktör "Üst Yönetim Desteği ve Gelișmiş İnsan Gücü" şeklinde isimlendirilmiştir. Faktör analizinden elde edilen sonuçlara göre tedarik zinciri ilişkilerinin başarısında 'Güven ve Sorumluluk' faktörü 1. sırada yer alırken, 'Üst Yönetim Desteği've 'Gelişmiş İnsan Gücü'2. sırada, 'Ortak Amaca Taahhüt'3. sırada, 'Stratejik Hedefler ve Esneklik'faktörü 4. sırada ve 'İşbirliği için Uygun Zincir Üyeleri Oluşturma’ faktörü 5. sıradadır. 
Çizelge 3. İnşaat sektöründe tedarik zinciri ilişkilerinin başarısını etkileyen faktör bileşenlerinin döndürülmüş faktör yükleri

\begin{tabular}{|c|c|c|c|c|c|}
\hline \multirow{2}{*}{ Bileșen (Etmen) } & \multicolumn{5}{|c|}{ Faktör } \\
\hline & 1 & 2 & 3 & 4 & 5 \\
\hline $\begin{array}{l}\text { 14.İhale sürecinin basitleşmesi } \\
\text { 5.Uzun vadeli bakışş̧ı̧ı } \\
\text { 3.Aamaç ve hedefşeffaflığ } 1 \\
\text { 8.Esneklik } \\
\text { 6.Taahhüt } \\
\text { 10.Daha sık toplantılar } \\
\text { 12. Karşıllklı çıarların gözetilmesi } \\
\text { 16. Firmalar arasında işbirliği kültürü } \\
\text { 15. Tedarikçi seçimine ve türüne dikkat } \\
\text { 17. Sektórde başarırlı örnekler } \\
\text { 1. Karşıllkklı Güven } \\
\text { 4. Sorumluluk duygusu } \\
\text { 1. İnsan gücü geliştirme } \\
\text { 2. Üst yönetim desteği }\end{array}$ & $\begin{array}{l}, 790 \\
, 706 \\
.640 \\
572\end{array}$ & $\begin{array}{l}, 773 \\
, 706 \\
, 510\end{array}$ & $\begin{array}{l}, 775 \\
, 714 \\
, 708\end{array}$ & $\begin{array}{l}, 871 \\
, 617\end{array}$ & $\begin{array}{l}.758 \\
.584\end{array}$ \\
\hline
\end{tabular}

\section{SONUÇLAR}

İnşaat tedarik zincirinde taraflar arasında koordinasyonu geliştirmek için ana yüklenici ve tedarikçi ilişkileri kritik öneme sahiptir. Tedarikçiler ile karşılıklı ilişkiler daha yüksek verimlilik düzeyine, daha yüksek kâra ve güvenilir bir ortama yol açar. Bu araştırmanın sonuçlarına göre, inşaat sektöründe tedarik zinciri ilişkilerinin başarısı için, taraflar arasında "güven" en önemli faktördür. Güvene dayalı bir işbirliği tedarik zincirinin tüm faaliyetleri için bir temeldir. $\mathrm{Bu}$ ilişkilerin başarısında ayrıca, "sorumluluk duygusu", “taahhüt”, “üst yönetim desteği”, "karşılıklı çıkarların gözetilmesi”, “insan gücü geliştirme", "kesintisiz bilgi akışı", sık toplantılar" gibi bileşenler de önemlidir.

$\mathrm{Bu}$ araştırmada, inşaat sektöründe tedarik zinciri ilişkilerinin başarılı olabilmesinde önemli olan faktörler, alt bileşen özellikleri göz önünde tutularak; "Güven ve Sorumluluk", "Üsst Yönetim Desteği ve Gelişmiş İnsan Gücü”, “Ortak Amaca Taahhüt", "Stratejik Hedefler", "Esneklik ve İşbirliği için Uygun Zincir Üyeleri Oluşturma", şeklinde isimlendirilmiştir.

\section{TEŞEKKÜR}

Bu çalışma Çukurova Üniversitesi Bilimsel Araştırma Projeleri Birimi tarafından desteklenmiştir (Proje no: MMF2012D13).

\section{KAYNAKLAR}

1. O'brien, M.J., Fischer, M.A., Jucker, J.V., 1995. An Economic View on Project Co-ordination. Construction Management and Economics 13 (5), 393-400.

2. Winch, G.M. 1989. The Construction Firm and the Construction Project: A Transaction Cost Approach. Construction Management \& Economics, Vol.7, pp. 331-345.

3. Oral. L, E., Kurt, D., 2000. Tam Zamanında Satınalma Sisteminin İnşaat Malzeme Yönetimine Uygulanabilirliği; 2.Yapı İşletmesi Kongresi Bildiriler Kitab1, İzmir Baş saray Basımevi, 15-17 Haziran 2000.

4. Kekre, S., Murthi, B.P.S., Srinivasan, K. 1995. Operating Decisions, Supplier Availability and Quality: An Empirical Study. Journal of Operations Management 12, Pp. 387-396.

5. Lummus, R., Vokurka, R. J., 1999. Defining Supply Chain Management: A Historical Perspective and Practical Guidelines. Industrial Management \& Data Systems 99/1, 11-17.

6. Egan, J., 1998. Rethinking Construction: The Report of the Construction Task Force. London, Department of the Environment, Transport and the Regions.

7. Vrijhoef, R., Koskela, L., 2000. The Four Roles of Supply Chain Management in Construction. European Journal of Purchasing \& Supply Management, 6, 169-178.

8. Choi, T, Y., Hartly, J, L., 1996. An Exploration of Supplier Selection Practices Across the Supply Chain. Journal of Operations Management 14, P. 333-343.

9. Akintoye, A, Mcintosh, G., Fitzgerald, F., 2000. A Survey of Supply Chain Collaboration and Management in the UK Construction Industry, European Journal of Purchasing \& Supply Management 6, 159-168.

10. Lambert, D. M., Cooper, M.C., Pagh, J.D., 1998. Supply Chain Management: İmplementation Issues and Research Opportunities. International Journal of Logistics Management, Vol. 9, No. 2, 1-18.

11. Wong, A., Fung, P., 1999. TQM in the Construction Industry in Hong Kong: A Supply Chain Management Perspective. Total Quality Management 10 (2), 199-208. 
12. Dale, B.G., Lascelles, D.M., Lloyd, A., 1994. Supply Chain Management and Development. Managing Quality. Prentice-Hall, London, pp. 292-315.

13. Bayram, N., 2004. Sosyal Bilimlerde SPSS ile Veri Analizi. 1. Bask1, 4 Nokta Matbaacılık, Bursa.

14. Tan, K. C.A., 2001. Framework of Supply Chain Management Literature, European Journal of Purchasing and Supply Management, vol. 7, No. 1, s. 39-48.

15. Swink, M. 2006. Building Collaborative Innovation Capability, Research-Technology Management, March-April, 37-47. 
